\title{
Sperm performance under hypoxic conditions in the intertidal fish Porichthys notatus
}

\author{
John L. Fitzpatrick, Paul M. Craig, Carol Bucking, Sigal Balshine, Chris M. Wood, \\ and Grant B. McClelland
}

\begin{abstract}
Hypoxia (low oxygen) exposure generally leads to decreased reproductive capacity, exhibited by reductions in testicular mass, reproductive hormones, and sperm swimming speed. However, in many fish species, reproduction occurs either periodically or exclusively under hypoxic conditions. In this study we assessed how hypoxia influences sperm performance in the plainfin midshipman (Porichthys notatus Girard, 1854), a species that lives in intertidal nests that become hypoxic during low tides. We exposed sperm from the same male to normoxic or hypoxic conditions and compared sperm characteristics and oxygen consumption between treatments. Sperm exposed to hypoxic water swam faster and consumed more oxygen than sperm swimming in normoxic conditions. Sperm swimming speed was positively related with oxygen consumption. For each male, the percentage of motile spermatozoa did not differ between treatments, suggesting that the same number of sperm were active but their performance was dependent on the dissolved oxygen content in the water. We discuss the implications of our results in the context of sperm competition and fertilization success under hypoxic conditions.
\end{abstract}

Résumé : Une exposition à l'hypoxie (faibles concentrations d'oxygène) mène généralement à une diminution de la capacité reproductive, ce qui se manifeste par une réduction de la masse testiculaire, des hormones reproductives et de la vitesse de nage des spermatozoïdes. Cependant, chez plusieurs espèces de poissons, la reproduction a lieu périodiquement ou même exclusivement dans des conditions d'hypoxie. Dans notre étude, nous évaluons les influences de l'hypoxie sur la performance des spermatozoïdes chez le pilotin tacheté (Porichthys notatus Girard, 1854), une espèce qui vit dans des nids intertidaux qui deviennent hypoxiques à marée basse. Nous avons exposé les spermatozoïdes d'un même mâle à des conditions normoxiques ou hypoxiques et avons comparé les caractéristiques des spermatozoïdes et leur consommation d'oxygène dans les deux conditions expérimentales. Les spermatozoïdes exposés à l'eau hypoxique nagent plus rapidement et consomment plus d'oxygène que les spermatozoïdes qui nagent en conditions normoxiques. Il y a une relation positive entre la vitesse de nage des spermatozoïdes et leur consommation d'oxygène. Chez un même mâle, le pourcentage de spermatozoïdes mobiles ne varie pas d'un traitement à l'autre, ce qui laisse croire qu'il y a le même nombre de spermatozoïdes en activité, mais que leur performance dépend de la concentration d'oxygène dissous dans l'eau. Nous discutons des implications de nos résultats dans le cadre de la compétition spermatique et du succès de la fécondation dans des conditions hypoxiques.

[Traduit par la Rédaction]

\section{Introduction}

Environmental exposure to hypoxia (low oxygen) typically impairs reproductive functions in males. For example, in humans, rodents, and primates, males exposed to hypobaric hypoxia have disrupted testicular development, produce fewer sperm, and have reduced reproductive hormone concentrations (Donayre 1968; Gonzales et al. 1990; Saxena 1995; Gasco et al. 2003; Farias et al. 2005, 2008; Verratti et al. 2008). Similarly, in fish, aquatic hypoxia is now recognized as an endocrine disruptor, with chronic hypoxic exposure leading to reductions in testicular mass, androgen levels, and sperm number in an ejaculate (Wu et al. 2003; Carter and Wilson 2006). Hypoxia may particularly impact

Received 4 December 2008. Accepted 30 March 2009. Published on the NRC Research Press Web site at cjz.nrc.ca on 7 May 2009.

J.L. Fitzpatrick, ${ }^{\mathbf{1}, 2}$ P.M. Craig, C. Bucking, C.M. Wood, and G.B. McClelland. Department of Biology, McMaster University, 1280 Main Street West, Hamilton, ON L8S 4K1, Canada; Bamfield Marine Sciences Centre, 100 Pachena Road, Bamfield, BC V0R 1B0, Canada.

S. Balshine. Animal Behaviour Group, Department of Psychology, Neuroscience and Behaviour, McMaster University, Hamilton, ON L8S 4K1, Canada.

${ }^{1}$ Corresponding author (e-mail: jfitzpat@cyllene.uwa.edu.au).

${ }^{2}$ Present address: Centre for Evolutionary Biology, School of Animal Biology, M092, University of Western Australia, Crawley, WA 6009, Australia. 
sperm performance, as the flagella (tails) of sperm are powered by adenosine triphosphate (ATP) generated in the sperm midpiece via oxidative phosphorylation, a process that strongly relies on the presence of oxygen (Billard and Cosson 1990). Indeed, in the mammals and fishes studied to date, males exposed to hypoxia produce ejaculates with slower swimming sperm (Saxena 1995; Bencic et al. 1999a, 1999b; Wu et al. 2003; Farias et al. 2008; Verratti et al. 2008) and fewer motile cells (Farias et al. 2008) compared with males maintained under normoxic conditions. Because fertilization success is related to sperm performance (e.g., Levitan 2000; Gage et al. 2004; Malo et al. 2005), hypoxiainduced impairments in sperm function may exacerbate the harmful effects of hypoxia, thereby further reducing male reproductive success.

Despite the negative impacts of hypoxia on reproduction, many externally fertilizing fish species reproduce under hypoxic conditions, shedding their gametes into hypoxic water. However, the handful of studies conducted on fish sperm performance under hypoxic conditions have examined species that typically avoid spawning in hypoxic water (Bencic et al. 1999a, 1999b; Wu et al. 2003). Therefore, it remains unclear how sperm respond to hypoxia in species that habitually experience hypoxic conditions. Here, we examined the effects of hypoxia on sperm performance in the plainfin midshipman (Porichthys notatus Girard, 1854). Midshipmen breed off the coast of North America from late spring to early summer (Arora 1948; DeMartini 1988), where large males (termed type I males; Brantley and Bass 1994) build and defend nests under rocks in the intertidal zone. Males remain on these nests throughout the reproductive season, acoustically courting females, spawning under rocks with receptive females, and caring for eggs that are deposited (Brantley and Bass 1994). During low tides males are often stranded in their nests in small pools of water and, like many intertidal organisms, face dramatic reductions in available oxygen content during low tides (McMahon 1988). As spawning in midshipmen occurs throughout the tidal cycle (Brantley and Bass 1994; Lee and Bass 2004), sperm released during low tides will face a hypoxic insult. Yet contrary to the pattern observed in other hypoxia-intolerant species, we found that exposure to hypoxic waters improved sperm performance in plainfin midshipman.

\section{Materials and methods}

Males were collected from nests in Mill Bay, British Columbia, Canada $\left(48^{\circ} 63^{\prime} \mathrm{N}, 123^{\circ} 53^{\prime} \mathrm{W}\right)$, during low tides on 15 June 2007. Males were transported to the laboratory in aerated seawater baths and maintained in $10-13{ }^{\circ} \mathrm{C}$ aerated seawater baths prior to the experiment. Dissolved oxygen (DO) content of nest water was measured from six airexposed nests at three points in the tidal cycle corresponding to air exposure for 1,2 , and $3 \mathrm{~h}$. The DO values from these six nests were compared with measures from six intertidal beach locations that remained covered in seawater. The duration that the nest was exposed to air did not influence DO content $\left(F_{[2,2]}=0.12, p=0.89\right)$ and therefore DO measures were combined to generate a single mean value per nest.

In the laboratory, eight males were given a lethal dose of anaesthetic (MS-222) and their testes were quickly removed and placed on a clean, dry-mass boat. Testes were split with a scalpel to obtain sperm. We used a nested design, exposing sperm samples from each male to both normoxic and hypoxic waters. Normoxic water was made hypoxic by bubbling nitrogen into the water. Therefore, sperm from the same male were exposed to water that was chemically equivalent aside from DO content. For half of the males, sperm were exposed to normoxic water first and hypoxic water second, while in the other half of the males sampled, sperm were exposed to hypoxic water first and normoxic water second. Sperm swimming speed and oxygen consumption were measured simultaneously for each sample as outlined below.

\section{Sperm swimming speed}

Approximately $1 \mu \mathrm{L}$ of milt (sperm and seminal plasma) obtained from the testes was placed in a $2.0 \mathrm{~mL}$ microcentrifuge tube and diluted by rapidly adding $0.5 \mathrm{~mL}$ of normoxic or hypoxic seawater to activate sperm. A subsample of the sperm and water mixture $(60 \mu \mathrm{L})$ was placed on a prefocused $1 \mathrm{~mm}$ deep-welled slide with a cover slip covering half of the depression as quickly as possible. The cover slip was then moved over the entire depression and cooking oil was placed around the cover slip to prevent uptake of oxygen from the atmosphere. Sperm motility was recorded from the moment sperm were diluted with seawater and was captured at 60 frames $\cdot \mathrm{s}^{-1}$ under $200 \times$ magnification with a PixeLINK Megapixel PL-A662 digital video camera (PixeLINK, Ottawa, Ontario, Canada) mounted on a Leica DME light microscope (Leica Microsystems Inc., Buffalo, New York, USA). Images were recorded using PixeLINK PL-A600 Series Camera Software (version 3.1).

Videos of motile sperm were analyzed in the laboratory. Sperm velocity was assessed at 4 time periods (4, 8, 12, and 16 min postactivation) using NIH ImageJ computerassisted sperm analysis (CASA) software (Wilson-Leedy and Ingermann 2007; ImageJ version 1.37, available at http://rsb.info.nih.gov/ij/ [accessed 8 February 2008], and the CASA plugin, available at http://rsb.info.nih.gov/ij/ plugins/casa.html [accessed 8 February 2008]). Although the CASA software examines several parameters, we focused on the percentage of motile spermatozoa, as well as on three commonly used measures of sperm swimming speed: curvilinear velocity (VCL), smooth-path velocity (VAP), and straight-line velocity (VSL) (for additional information see Wilson-Leedy and Ingermann 2007). We chose these sperm parameters because they are known to reflect fertilization success in a broad range of species (Denk et al. 2005; Malo et al. 2005; Casselman et al. 2006; Liljedal et al. 2008). Videos of motile sperm were assessed during the first $10 \mathrm{~s}$ after each of the four time periods. We only examined sperm where swimming speed was recorded for a minimum of $0.5 \mathrm{~s}$. CASA software settings were adjusted for each sample. However, generally CASA settings were as follows: sperm head size ranging from 50-120 pixels (this range was required to capture spermatozoa that were viewed at different levels of focus), a maximum sperm velocity between frames of 40 pixels, and VCL, VAP, and VSL values less than $10 \mu \mathrm{m} \cdot \mathrm{s}^{-1}$ were considered immotile. The mean $( \pm \mathrm{SE})$ number of spermatozoa recorded at each time period was $115.8 \pm 7.8$. The ob- 
Table 1. Results of repeated-measures ANOVAs examining the effect of treatment (hypoxic and normoxic), time since activation, and the interaction between treatment and time on curvilinear velocity (VCL), smooth-path velocity (VAP), and straight-line velocity (VSL) of sperm of plainfin midshipmen (Porichthys notatus) recorded at four time periods postactivation.

\begin{tabular}{llrccl}
\hline Velocity measure & Effect & \multicolumn{1}{c}{$F$} & df & \multicolumn{1}{c}{$p$} & $r^{2}$ adjusted \\
\hline VCL & Treatment & 6.21 & 1,12 & 0.03 & 0.74 \\
& Time & 43.20 & 3,36 & $<0.0001$ & \\
VAP & Time $\times$ treatment & 0.60 & 3,36 & 0.62 & \\
& Treatment & 5.14 & 1,12 & 0.04 & 0.83 \\
& Time & 71.95 & 3,36 & $<0.0001$ & \\
VSL & Time $\times$ treatment & 3.21 & 3,36 & 0.03 & \\
& Treatment & 2.27 & 1,12 & 0.16 & 0.63 \\
& Time & 29.46 & 3,36 & $<0.0001$ & \\
& Time $\times$ treatment & 0.45 & 3,36 & 0.71 & \\
\hline
\end{tabular}

jective remained in a fixed position and the microscope stage was not moved throughout the experiment. Because sperm movement far exceeded the field of view, it is unlikely that the same spermatozoa were measured at different time periods.

Sperm velocity has not been examined in plainfin midshipman before. Therefore, to validate the CASA measurement obtained in this study, we contrasted the sperm velocity measures obtained using CASA (VCL, VAP, VSL) with values obtained by tracking a subset of sperm cells $\left(9.1 \pm 0.3 \mathrm{sperm} \cdot(\text { time period })^{-1}\right)$, by following the center of the sperm's head for $76.6 \pm 1.1$ frames, at each time period using the ImageJ manual tracking function (http://rsbweb. nih.gov/ij/plugins/track/track.html [accessed 8 February 2008]). Sperm velocity values obtained from CASA were highly correlated with those obtained by manually tracking spermatozoa (VCL: $r^{2}=0.74$; VAP: $r^{2}=0.82$; VSL: $r^{2}=$ $0.77)$. Because measures obtained by manually tracking sperm are most equivalent to the VAP calculated from sperm tracking software, it is not surprising that VAP was most closely related with values obtained by manually tracking cells.

\section{Sperm oxygen consumption}

Oxygen consumption was measured using a model 782 oxygen meter attached to a laptop computer and a model 1302 Clarke-type polarographic oxygen electrode (Strathkelvin Instruments, North Lanarkshire, Scotland). The electrode fits into a glass cell (16 mm diameter, $1 \mathrm{~mL}$ volume) fused to a glass water jacket that had seawater pumped through it, maintaining a constant temperature of $11{ }^{\circ} \mathrm{C}$. A sample of milt $\left(11.0 \times 10^{6} \pm 1.3 \times 10^{6}\right.$ spermatozoa $\cdot$ sample $^{-1}$; mean $\pm \mathrm{SE}$ ) was collected and placed in $2.0 \mathrm{~mL}$ microcentrifuge tube with $1.5 \mathrm{~mL}$ of aerated or hypoxic seawater. The electrodes were calibrated with air-saturated seawater prior to each sample measurement. A $1 \mathrm{~mL}$ sample of the sperm and water solution was injected with a 22-gauge needle through a small opening into the glass cell. This allowed air and excess water to be removed. One chamber was injected with a sample of sperm swimming in either normoxic or hypoxic water, while a seawater control sample was injected into another. The seawater control was used to account for oxygen consumption of the electrode. The DO content in the normoxic seawater was $9.39 \pm$ $0.07 \mathrm{mg} \cdot \mathrm{L}^{-1}$, while the DO content in the hypoxic condi- tion was $4.56 \pm 1.0 \mathrm{mg} \cdot \mathrm{L}^{-1}$, representing DO levels that were $48.6 \%$ that of the normoxic condition. The DO content in the hypoxic condition was just above the range of DO observed in nests of midshipmen (see Results below). Oxygen consumption was measured simultaneously from both cells, after which a $750 \mu \mathrm{L}$ sample of the sperm and water solution was placed in 5\% buffered formalin. Sperm density was measured under a microscope using a haemocytometer and oxygen consumption was calculated as milligrams of oxygen consumed per sperm per minute.

\section{Statistical analyses}

All analyses were performed using JMP version. 5.0 (SAS Institute Inc. 2002). Since data did not meet the assumptions of normality, we analyzed data using repeated-measures ANOVAs on ranked data (Zar 1999). Male identity was nested within treatment when assessing differences in sperm swimming speed and oxygen consumption between treatments (normoxic vs. hypoxic). Thus our analysis determined if there were differences between treatments while accounting for male identity. When examining the relationship between sperm swimming speed and oxygen consumption, treatments (hypoxic and normoxic) were grouped together and assessed independently, with time added as a covariate and male identity added as a random effect to the model. Data on the percentage of motile spermatozoa were arcsinetransformed prior to analyses (Zar 1999). Oxygen consumption was not collected successfully for one male and one of the sperm videos was corrupted for another male, decreasing the sample size to seven for these analyses.

\section{Results}

Dissolved oxygen content in nests $\left(3.40 \pm 0.09 \mathrm{mg} \cdot \mathrm{L}^{-1}\right.$, range $2.4-4.3 \mathrm{mg} \cdot \mathrm{L}^{-1}$ ) was $64 \%$ lower than the dissolved oxygen content in seawater $\left(9.54 \mathrm{mg} \cdot \mathrm{L}^{-1}\right)$.

Dissolved oxygen levels in the water influenced both sperm swimming speed and oxygen consumption. Sperm swimming speed decreased over time in both normoxic and hypoxic waters (repeated-measures ANOVA on ranks, $\left.F_{[3,42]}=19.83, p<0.0001\right)$, but overall, sperm in hypoxic water swam faster than sperm from the same male swimming in normoxic water when VCL and VAP were assessed (Table 1, Fig. 1a). Although there was no difference in VSL between treatments in the full model (Table 1), when the 
Fig. 1. (a) Swimming speed (measured as curvilinear velocity $(\mathrm{VCL})$ ) and (b) oxygen consumption of sperm of plainfin midshipmen (Porichthys notatus) exposed to normoxic and hypoxic waters.
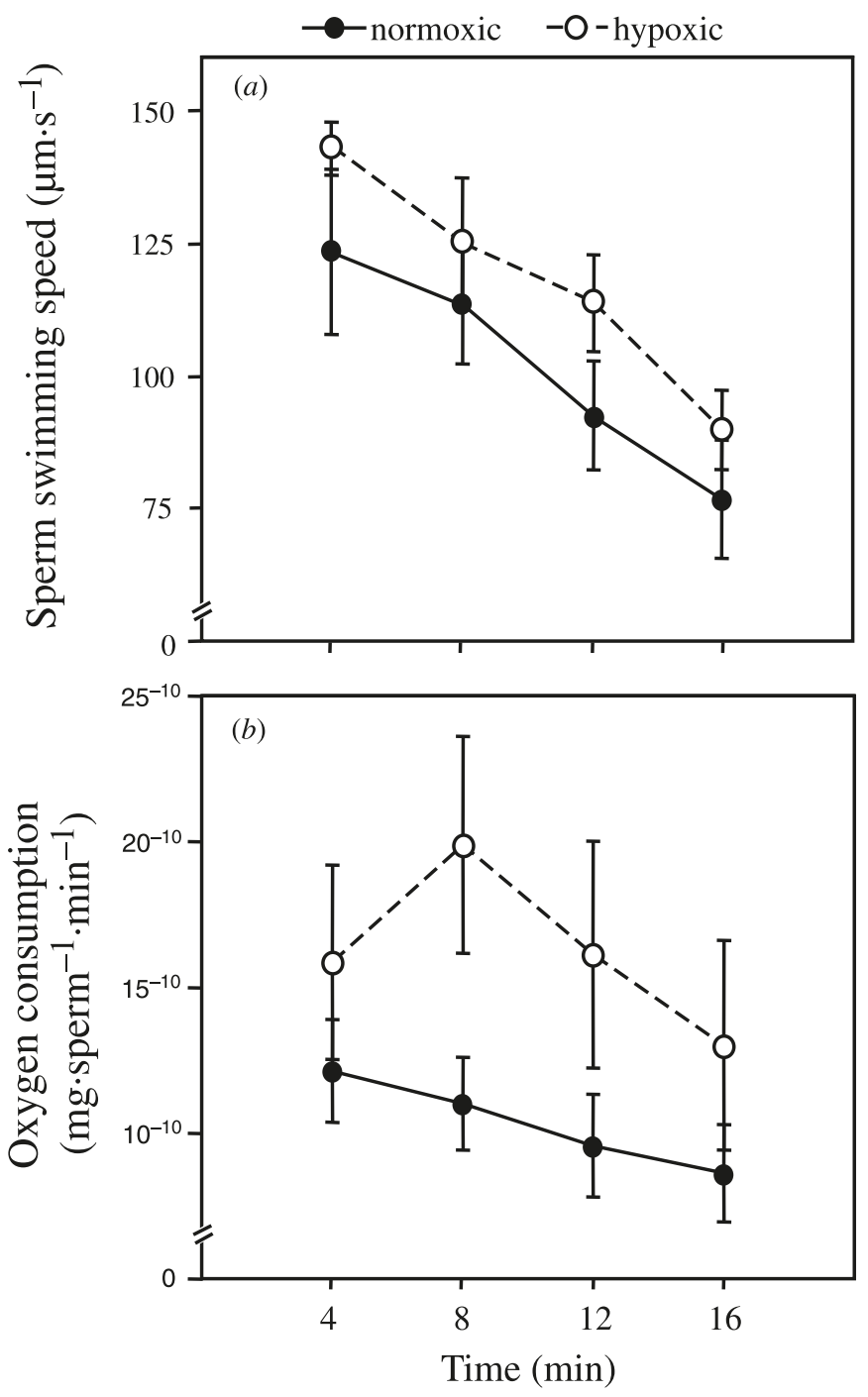

nonsignificant interaction term was removed from the model, sperm swimming in hypoxic water had significantly higher VSL values than when swimming in normoxic water $\left(F_{[1,12]}=8.88, p=0.01\right)$. Sperm swimming in hypoxic water also consumed oxygen at higher rates than sperm swimming in normoxic water $\left(F_{[1,12]}=7.35, p=0.02\right.$; Fig. $\left.1 b\right)$. The rate of oxygen consumption decreased over time in both treatments $\left(F_{[3,39]}=4.89, p=0.006\right)$. In both treatments, the percentage of motile cells decreased over time $\left(F_{[3,36]}=\right.$ $23.84, p<0.001)$, from $47.1 \% \pm 0.1 \%$ motile at 4 min postactivation to $21.3 \% \pm 0.04 \%$ motile at 16 min postactivation. However, in contrast to sperm velocity and oxygen consumption, there was no effect of the treatment on the percentage of motile cells $\left(F_{[1,12]}=0.04, p=0.85\right)$.

Across all the samples, there was a positive relationship between sperm swimming speed and oxygen consumption (VCL: $F_{[1,38]}=7.94, p=0.008$; VAP: $F_{[1,38]}=7.76, p=$ 0.008 ; VSL: $\left.F_{[1,38]}=7.14, p=0.01\right)$. When treatments were assessed independently, under hypoxic conditions sperm velocity was positively related with oxygen consumption
$\left(\mathrm{VCL}: F_{[1,14]}=19.01, p<0.001 ; \mathrm{VAP}: F_{[1,14]}=12.13, p=\right.$ 0.004 ; VSL: $\left.F_{[1,14]}=9.02, p=0.01\right)$; however, there was no such relationship when sperm swam in normoxic conditions (for all velocity measures $p \geq 0.24$ ). There was no relationship between oxygen consumption and percentage of motile $\operatorname{sperm}\left(F_{[1,42]}=0.15, p=0.70\right)$.

\section{Discussion}

We show that sperm from plainfin midshipmen exposed to hypoxic conditions swam faster and consumed more oxygen than sperm exposed to normoxic conditions. By exposing sperm from the same male to different treatments, we were able to account for variation in sperm performance between males while directly assessing the effect of dissolved oxygen content in the water. When sperm from the same male was exposed to water with different oxygen content, the total number of motile sperm (\% motile) remained constant. This suggests that for each male the same number of sperm were active, but the performance (speed and oxygen consumption) of motile sperm reflected the environmental conditions in which sperm were swimming. Furthermore, the positive relationship between sperm swimming speed and oxygen consumption suggests that sperm were able to increase speed by increasing the rate of oxidative phosphorylation, a process that relies on the consumption of oxygen. Because ATP is produced via oxidative phosphorylation, these results imply that reductions in DO content in the water were associated with increases in ATP production in sperm.

The observed increase in sperm swimming speed in hypoxic water may have important fitness consequences. Sperm swimming speed is an important predictor of fertilization success in many species (Froman et al. 1999; Levitan 2000; Au et al. 2002; Malo et al. 2005), particularly in contested fertilizations (i.e., sperm competition) where more than one male releases sperm in an attempt to fertilize a female's ova (Birkhead et al. 1999; Gage et al. 2004; Denk et al. 2005; Casselman et al. 2006; Liljedal et al. 2008). Therefore, given the increase in sperm swimming speed when DO content was reduced, our results suggest that sperm competitiveness may be enhanced under hypoxic conditions. However, our finding of enhanced sperm performance in hypoxic waters stands in stark contrast with the effects demonstrated in other species. In the common carp (Cyprinus carpio L., 1758) and salmonids such as rainbow trout, Oncorhynchus mykiss (Walbaum, 1792), and chinook salmon, Oncorhynchus tshawytscha (Walbaum in Artedi, 1792), sperm exposed to hypoxic conditions exhibited reduced performance, with a decline in the percentage of motile spermatozoa and sperm swimming speed (Bencic et al. 1999a, 1999b; Wu et al. 2003). Similarly, mammalian studies consistently demonstrate a reduction in sperm performance after exposure to hypobaric hypoxia (see references in the Introduction).

It is unclear how sperm are able to swim faster while consuming more oxygen under hypoxic conditions. One possibility is that sperm from plainfin midshipmen are usually ejaculated under hypoxic conditions and therefore normoxic water may represent hyperoxygenated conditions. However, this idea seems unlikely, as behavioural observations indicate that spawning occurs throughout the tidal cycle 
(Brantley and Bass 1994; Lee and Bass 2004; J.L. Fitzpatrick, personal observations). Alternatively, when swimming in normoxic water, sperm may produce more reactive oxygen species (e.g., superoxide $\left(\mathrm{O}_{2}^{-}\right)$, hydroxyl radicals $\left(\mathrm{OH}^{-}\right)$, hydrogen peroxide $\left(\mathrm{H}_{2} \mathrm{O}_{2}\right)$ ) in the mitochondria, causing a moderate uncoupling of the electron transport chain and subsequently sacrificing ATP production to reduced oxidative damage (Jamieson et al. 1986; Brand et al. 2004). Since sperm swimming speed is related to sperm ATP content and rate of ATP production (e.g., Christen et al. 1987; Bencic et al. 1999a; Burness et al. 2004), a process that relies on oxygen consumption, impaired mitochondrial efficiency would be evident in reduced sperm swimming speeds and reduced rates of oxygen consumption, as found in sperm swimming in normoxic water in this study. Finally, every mitochondria in cells of plainfin midshipmen may be optimized for peak performance under hypoxic conditions, as midshipman are an extremely hypoxia tolerant species (Martin 1995). If this were the case, then the same mitochondria that support general cellular functions under hypoxia would also be present in spermatozoa allowing sperm to swim faster under hypoxic conditions. Further work is needed to tease apart these alternatives.

In this study we focused on nest guarding type I male midshipmen. However, in midshipmen there are two types of males, type I and type II males (Brantley and Bass 1994), that use different tactics to obtain fertilizations and therefore experience dramatically different selective pressures when mating. While type I males guard nests, court females, and rear eggs, smaller type II males attempt to parasitize reproduction from type I males (Brantley and Bass 1994). Type II males do not court females, but instead invest energy into reproduction and sneaky mating attempts (Brantley and Bass 1994). This creates an asymmetry in the degree of sperm competition that males face during mating. Type II males always experience sperm competition, while type I males only experience sperm competition when a competing male is present in the nest. Consequently, theory predicts that sperm performance will be enhanced in sneaking type II males (Ball and Parker 1996). Recently, we showed that type II males had faster swimming sperm than type I males under normoxic conditions (Fitzpatrick 2008). Type II males may be able to augment their advantage by producing still faster swimming sperm under hypoxic conditions. Alternatively, if plastic responses in sperm performance to oxygen levels are confined to type I males, this suggests that the outcome of competition between ejaculates of type I and type II may be dependent on the physical environment into which sperm are ejaculated. Specifically, when both females and type II males are present, and consuming oxygen, in the nest of a type I male then water oxygen levels should decrease, which may act as a cue of increased competition. Therefore, sperm from type I males that swim faster in hypoxic conditions may represent a response to cues of sperm competition. In future investigations, it will be of interest to examine if there are tacticspecific differences in responses in sperm to hypoxic conditions.

Our findings of improved sperm performance under hypoxic conditions are at odds with responses observed in other mammalian and fish species. To date, few studies have assessed sperm swimming performance under hypoxic conditions in species that habitually reproduce in hypoxic water. Our results may represent an adaptation to reproduction in hypoxic waters and may be applicable to a wide range of species that reproduce in temporarily or permanently hypoxic water (McMahon 1988). A critical next step is gaining a better understanding of the mitochondrial processes that are facilitating enhanced sperm performance under hypoxic conditions in midshipman. Additionally, examinations of sperm characteristics in species that reproduce in hypoxic conditions would help to demonstrate if this phenomenon is widely applicable to organisms that regularly encounter low oxygen.

\section{Acknowledgements}

We thank the Director and Staff of Bamfield Marine Sciences Centre for their help and cooperation during this study. We especially thank the Research Co-ordinator, Bruce Cameron, for his assistance during this study. We also thank S. Marsh-Rollo for providing logistical support while in the field, P. Walsh for assisting with fish collection, and R.W. Smith for insightful discussions. This work was funded by a Natural Sciences and Engineering Research Council of Canada (NSERC) Discovery Grant to C.M.W., a NSERC Discovery Grant and an Ontario Ministry of Innovation Early Researcher Award to G.B.M., a NSERC Discovery Grant and a Canadian Foundation for Innovation and Ontario Innovation Trust awarded to S.B., and a Canadian Society of Zoologists Student Travel Research Grant to J.L.F. C.B, J.L.F., and P.C. were supported by NSERC postgraduate scholarships. C.M.W. and S.B. are supported by the Canada Research Chair Program.

\section{References}

Arora, H.L. 1948. Observations of the habits and early life history of the Batrachoid fish, Porichthys notatus Girard. Copeia, 1948: 89-93. doi:10.2307/1438409.

Au, D.W.T., Chiang, M.W.L., Tang, J.Y.M., Yuen, B.B.H., Wang, Y.L., and $\mathrm{Wu}$, R.S.S. 2002. Impairment of sea urchin sperm quality by UV-B radiation: predicting fertilization success from sperm motility. Mar. Pollut. Bull. 44: 583-589. doi:10.1016/ S0025-326X(01)00288-0. PMID:12222880.

Ball, M.A., and Parker, G.A. 1996. Sperm competition games: external fertilization and "adaptive" infertility. J. Theor. Biol. 180: 141-150. doi:10.1006/jtbi.1996.0090. PMID:8763365.

Bencic, D.C., Krisfalusi, M., Cloud, J.G., and Ingermann, R.L. 1999a. Maintenance of steelhead trout (Oncorhynchus mykiss) sperm at different in vitro oxygen tensions alters ATP levels and cell functional characteristics. Fish Physiol. Biochem. 21: 193-200. doi:10.1023/A:1007880426488.

Bencic, D.C., Krisfalusi, M., Cloud, J.G., and Ingermann, R.L. 1999b. ATP levels of chinook salmon (Oncorhynchus tshawytscha) sperm following in vitro exposure to various oxygen tensions. Fish Physiol. Biochem. 20: 389-397. doi:10.1023/ A:1007749703803.

Billard, R., and Cosson, M.P. 1990. The energetics of fish sperm motility. In Controls of sperm motility: biological and clinical aspects. Edited by C. Gagnon. CRC Press Inc., Boca Raton, Florida. pp. 153-173.

Birkhead, T.R., Martinez, J.G., Burke, T., and Froman, D.P. 1999. Sperm mobility determines the outcome of sperm competition in 
the domestic fowl. Proc. R. Soc. Lond. B Biol. Sci. 266: 17591764. doi:10.1098/rspb.1999.0843.

Brand, M.D., Affourtit, C., Esteves, T.C., Green, K., Lambert, A.J., Miwa, S., Pakay, J.L., and Parker, N. 2004. Mitochondrial superoxide: production, biological effects, and activation of uncoupling proteins. Free Radic. Biol. Med. 37: 755-767. doi:10. 1016/j.freeradbiomed.2004.05.034.

Brantley, R.K., and Bass, A.H. 1994. Alternative male spawning tactics and acoustic signals in the plainfin midshipman fish, Porichthys notatus Girard (Teleostei, Batrachoididae). Ethology, 96: 213-223.

Burness, G., Casselman, S.J., Schulte-Hostedde, A.I., Moyes, C.D., and Montgomerie, R. 2004. Sperm swimming speed and energetics vary with sperm competition risk in bluegill (Lepomis macrochirus). Behav. Ecol. Sociobiol. 56: 65-70. doi:10.1007/ s00265-003-0752-7.

Carter, A.J., and Wilson, R.S. 2006. Improving sneaky-sex in a low oxygen environment: reproductive and physiological responses of male mosquito fish to chronic hypoxia. J. Exp. Biol. 209: 4878-4884. doi:10.1242/jeb.02531. PMID:17142676.

Casselman, S.C., Schulte-Hostedde, A.I., and Montgomerie, R. 2006. Sperm quality influences male fertilization success in walleye (Sander vitreus). Can. J. Fish. Aquat. Sci. 63: 2119-2125. doi:10.1139/F06-108.

Christen, R., Gatti, J.L., and Billard, R. 1987. Trout sperm motility: the transient movement of trout sperm is related to changes in the concentration of ATP following the activation of the flagellar movement. Eur. J. Biochem. 166: 667-671. doi:10.1111/j. 1432-1033.1987.tb13565.x.

DeMartini, E.E. 1988. Spawning success of the male plainfin midshipman. I. Influences of male body size and area of spawning site. J. Exp. Mar. Biol. Ecol. 121: 177-192. doi:10.1016/00220981(88)90254-7.

Denk, A.G., Holzmann, A., Peters, A., Vermeirssen, E.L.M., and Kempenaers, B. 2005. Paternity in mallards: effects of sperm quality and female sperm selection for inbreeding avoidance. Behav. Ecol. 16: 825-833. doi:10.1093/beheco/ari065.

Donayre, J. 1968. Effect of high altitude on spermatogenesis. In Proceedings of the Third International Congress of Endocrinology, Distrito Federal, Mexico, 30 June - 5 July 1968. Excerpta Medica, Amsterdam. Edited by C. Gual and F.J.G. Ebling. Vol. 184. pp. 1054-1059.

Farias, J.G., Bustos-Obregón, E., Bucarey, J.L., Quiroz, E., and Reyes, J.G. 2005. Effects of chronic hypobaric hypoxia on testis histology and round spermatid oxidative metabolism. Andrologia, 37: 47-52. doi:10.1111/j.1439-0272.2004.00651.x. PMID: 15644063.

Farias, J.G., Bustos-Obregón, E., Tapia, P.J., Gutierrez, E., Zepeda, A., Juantok, C., Cruz, G., Soto, G., Benites, J., and Reyes, J.G. 2008. Time course of endocrine changes in the hypophysisgonad axis induced by hypobaric hypoxia in male rats. J. Reprod. Dev. 54: 18-21. doi:10.1262/jrd.19046. PMID:17984574.

Fitzpatrick, J.L. 2008. Sperm competition in fish. Ph.D. thesis, Department of Biology, McMaster University, Hamilton, Ont.

Froman, D.P., Feltmann, A.J., Rhoads, M.L., and Kirby, J.D. 1999. Sperm mobility: a primary determinant of fertility in the domestic fowl (Gallus domesticus). Biol. Reprod. 61: 400-405. doi:10. 1095/biolreprod61.2.400. PMID:10411518.

Gage, M.J.G., Macfarlane, C.P., Yeates, S., Ward, R.G., Searle,
J.B., and Parker, G.A. 2004. Spermatozoal traits and sperm competition in Atlantic salmon: relative sperm velocity is the primary determinant of fertilization success. Curr. Biol. 14: 44-47. PMID:14711413.

Gasco, M., Rubio, J., Chung, A., Villegas, L., and Gonzales, G.F. 2003. Effect of high altitude exposure on spermatogenesis and epididymal sperm count in male rats. Andrologia, 35: 368-374. doi:10.1046/j.0303-4569.2003.00593.x. PMID:15018139.

Gonzales, G.F., Rodriguez, L., Valera, J., Sandoval, E., and Garcia-Hjarles, M. 1990. Prevention of high altitude-induced testicular disturbances by previous treatment with cyproheptadine in male rats. Arch. Androl. 24: 201-205. doi:10.3109/ 01485019008986880. PMID:2327830.

Jamieson, D., Chance, B., Cadenas, E., and Boveris, A. 1986. The relation of free radical production to hyperoxia. Annu. Rev. Physiol. 48: 703-719. doi:10.1146/annurev.ph.48.030186.003415. PMID:3010832.

Lee, J.S.F., and Bass, A.H. 2004. Does exaggerated morphology preclude plasticity to cuckoldry in the midshipman fish (Porichthys notatus)? Naturwissenschaften, 91: 338-341. doi:10. 1007/s00114-004-0531-y. PMID:15257389.

Levitan, D.R. 2000. Sperm velocity and longevity trade off each other and influence fertilization in the sea urchin Lytechinus variegates. Proc. R. Soc. Lond. B Biol. Sci. 267: 531-534. doi:10.1098/rspb.2000.1032.

Liljedal, S., Rudolfsen, G., and Folstad, I. 2008. Factors predicting male fertilization success in an external fertilizer. Behav. Ecol. Sociobiol. 62: 1805-1811. doi:10.1007/s00265-008-0609-1.

Malo, A.F., Garde, J.J., Soler, A.J., Garcia, A.J., Gomendia, M., and Roldan, E.R.S. 2005. Male fertility in natural populations of red deer is determined by sperm velocity and the proportion of normal spermatozoa. Biol. Reprod. 72: 822-829. doi:10.1095/ biolreprod.104.036368. PMID:15576823.

Martin, K.L.M. 1995. Time and tide wait for no fish: intertidal fishes out of water. Environ. Biol. Fishes, 44: 165-181. doi:10. 1007/BF00005914.

McMahon, B.R. 1988. Physiological responses to oxygen depletion in intertidal animals. Am. Zool. 28: 39-53.

SAS Institute Inc. 2002. JMP. Version. 5.0 [computer program], SAS Institute Inc., Cary, N.C.

Saxena, D.K. 1995. Effect of hypoxia by intermittent altitude exposure on semen characteristics and testicular morphology of male rhesus monkeys. Int. J. Biometeorol. 38: 137-140. doi:10.1007/ BF01208490. PMID:7744528.

Verratti, V., Berardinelli, F., Di Giulio, C., Bosco, G., Cacchio, M., Pellicciotta, M., Nicolai, M., Martinotti, S., and Tenaglia, R. 2008. Evidence that chronic hypoxia causes reversible impairment on male fertility. Asian J. Androl. 10: 602-606. doi:10. 1111/j.1745-7262.2008.00346.x. PMID:18097511.

Wilson-Leedy, J.G., and Ingermann, R.L. 2007. Development of a novel CASA system based on open source software for characterization of zebrafish sperm motility. Theriogenol. 67: 661-672.

Wu, R.S.S., Zhou, B.S., Randall, D.J., Woo, N.Y.S., and Lam, P.K. 2003. Aquatic hypoxia is an endocrine disruptor and impairs fish reproduction. Environ. Sci. Technol. 37: 1137-1141. doi:10. 1021/es0258327. PMID:12680666.

Zar, J.H. 1999. Biostatistical analysis. 4th ed. Prentice Hall, Inc., Upper Saddle River, N.J. 